\title{
New Disease Reports \\ Occurrence of a leaf spot disease of radish caused by Xanthomonas campestris pv. raphani in Italy
}

\author{
S. Loreti ${ }^{1 *}$, A.Gallelli $^{1}$, G. Perez ${ }^{1}$ and A. Schiappa ${ }^{2}$ \\ ${ }^{1}$ C.R.A. 7 Centro di Ricerca per la Patologia Vegetale, Via C. G. Bertero, 22, 00156 Roma, Italy ; ${ }^{2}$ Enza Zaden Italia \\ Research Srl - SS 1 Aurelia, 01016 Tarquinia (VT), Italy \\ *E-mail: stefania.loreti@entecra.it
}

Received: 21 Jul 2010. Published: 04 Apr 2011. Keywords: Raphanus sativus, bacteria, gyrB

In spring 2009, severe leaf spot symptoms were observed on radish growing in glasshouses in the Latium region of Italy. Discrete, water-soaked to greasy spots were observed on leaves, with some spots surrounded by a narrow yellow halo (Fig. 1). There was no evidence of marginal V-shaped lesions to indicate vascular black rot disease caused by Xanthomonas campestris pv. campestris $(\mathrm{Xcc})$. A bacterium that formed yellow colonies on yeast dextrose chalk agar and on nutrient agar was consistently isolated from these lesions. Four isolates (CRA-PAV1523, $1524,1525,1526)$ were purified and characterised.

All isolates elicited a typical hypersensitive reaction (HR) on bean pods at the site of inoculation with bacterial suspensions $\left(10^{8} \mathrm{cfu} / \mathrm{ml}\right)$. Pathogenicity was tested on radish (cvs. Donar and Celesta), capsicum pepper (cv. Quadrato d'Asti), tomato (cv. Roma), pumpkin (cv. Musque d'Hiver de Provence) and cucumber (cv. Marketmore). Bacterial suspensions of CRA-PAV1524 $\left(10^{8} \mathrm{cfu} / \mathrm{ml}\right)$ were sprayed onto both the upper and lower surfaces of leaves of ten replicate plants of each species with a hand held sprayer; eight control plants were inoculated with sterile distilled water. X. campestris NCPPB347 (Xc) [originally incorrectly attributed to pv. armoraciae (Vicente et al., 2006; Fargier and Manceau, 2007)], X.c. pv. raphani (Xcr) NCPPB1946, and Xcc ISPaVe1032 were also inoculated into radish. Leaf spot symptoms on radish induced by $X c r$ NCPPB1946 and CRA-PAV1524 appeared within 4 days (Fig. 2) and were more aggressive than symptoms induced by $X c$ NCPPB347; pin inoculation of the middle vein of expanded leaves (Vicente et al., 2006), showed black, sunken, elongated lesions on leaves inoculated with $\mathrm{Xcr}$ NCPPB1946 and CRA-PAV1524, but not with Xc NCPPB347. Xcc ISPaVe1032 produced dark spots and chlorosis that progressed towards typical V-shape yellow lesions. CRA-PAV1524 was pathogenic on capsicum pepper, pumpkin, tomato (weakly aggressive) and on cucumber (highly aggressive) (Fig. 3). Control plants did not show any symptoms. Re-isolations from symptomatic plants yielded bacterial colonies identical to those used for inoculations and with the same rep-PCR profiles.

Amplification of the gyrB gene (Parkinson et al., 2009) and BLAST analysis of the sequenced amplicons (GenBank Accession Nos. FR667199, FR667200, FR667201, FR667202) revealed a sequence identity of 98-99\% to $X c r$ NCPPB1946 (EU285222), also deposited as ICMP1404 (EU498982), Xc NCPPB347, X.c. pv. incanae ICMP574 and several Xcc strains (i.e. AE008922; EU499018; EU498948; AM920689). Phylogenetic

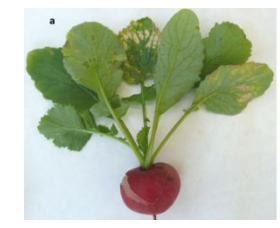

Figure 1
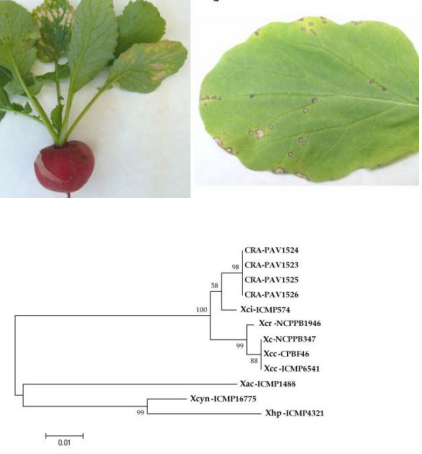

analysis performed with MEGA version 4.0 showed that all isolates grouped together with the $X$. campestris reference strains, well separated from other Xanthomonas species (Fig. 4). Based on the pathogenicity, host range and molecular characterisation, these isolates were identified as $X$. $c$. pv. raphani. X. c. pv. incanae is not pathogenic on radish (Vicente et al., 2001), Xcc develops different symptoms on radish, and the existence of X. c. pv. armoraciae is no longer supported (Vicente et al., 2006; Fargier and Manceau, 2007). To our knowledge this is the first report of $X$. c. pv. raphani on radish in Italy.

\section{References}

Fargier E, Manceau C, 2007. Pathogenicity assays restrict the species Xanthomonas campestris into three pathovars and reveal nine races within X. campestris pv. campestris. Plant Pathology 56, 805-818.

[doi:10.1111/j.1365-3059.2007.01648.x]

Parkinson N, Cowie C, Heeney J, Stead D, 2009. Phylogenetic structure of Xanthomonas determined by comparison of gyrB sequences. International Journal of Systematic and Evolutionary Microbiology 59, 264-274. [doi:10.1099/ijs.0.65825-0]

Vicente JG, Conway J, Roberts SJ, Taylor JD, 2001. Identification and origin of Xanthomonas campestris pv. campestris races and related pathovars. Phytopathology 91, 492-499.

\section{[doi:10.1094/PHYTO.2001-91.5.492]}

Vicente JG, Everett B, Roberts SJ, 2006. Identification of isolates that cause a leaf spot disease of brassicas as Xanthomonas campestris pv. raphani and pathogenic and genetic comparison with related pathovars. Phytopathology 96, 735-745. [doi:10.1994/PHYTO-96-0735]

Figure 4

To cite this report: Loreti S, A.Gallelli, Perez G, Schiappa A, 2011. Occurrence of a leaf spot disease of radish caused by Xanthomonas campestris pv. raphani in Italy. New Disease Reports 23, 17. [doi:10.5197/j.2044-0588.2011.023.017] 